\title{
A Control Parameters Design Method With Multi-Constrains for an LCL-Filtered Grid-Connected Inverter in a Weak Grid
}

OPEN ACCESS

Edited by: Ningyi Dai,

University of Macau, China

Reviewed by:

Yushuai Li,

University of Oslo, Norway

Xi Lu,

Southeast University, China

*Correspondence:

Jianguo Lyu

jianguolyu@njust.edu.cn

Specialty section:

This article was submitted to

Smart Grids,

a section of the journal

Frontiers in Energy Research

Received: 20 October 2021

Accepted: 16 December 2021

Published: 13 January 2022

Citation:

Wu F, Sun Z, Xu W, Li Z and Lyu J (2022) A Control Parameters Design Method With Multi-Constrains for an LCL-Filtered Grid-Connected Inverter in a Weak Grid.

Front. Energy Res. 9:798793. doi: 10.3389/fenrg.2021.798793

\author{
Fuyun $W u^{1}$, Zhuang Sun ${ }^{2}$, Weiji $X u^{2}$, Zhizhou $L i^{2}$ and Jianguo $L y u^{2 *}$ \\ ${ }^{1}$ College of Mechanical and Electrical Engineering, Sanjiang University, Nanjing, China, ${ }^{2}$ School of Automation, Nanjing University \\ of Science and Technology, Nanjing, China
}

Under weak grid conditions, the variation of the grid impedance will affect the steady-state and dynamic performance of the LCL-filtered grid-connected inverter and even make the inverter unstable. To ensure the system stability and further improve the dynamic performance in a weak grid, a control parameter design method with multi-constrains considering the system bandwidth for the current controller and active damping is proposed in this paper. First, based on the current controller and active damping with only grid current feedback, the effects of control parameters and grid impedance on the LCL resonant suppression and the performance of the inverter are analyzed. Moreover, the parameter constraints of the controllers are derived considering the grid impedance, including stability, resonance suppression, and margin constraints. Furthermore, as the system bandwidth affects the dynamic performance of the inverter, combined with the obtained multi-constraints, the optimal control parameters are determined by achieving the maximum bandwidth of the system against the impedance variation. Compared with other two methods, when the proposed method is applied, the system can operate with a better dynamic and steady-state performance. Finally, experiments are performed on a $2 \mathrm{~kW}$ three-phase grid-connected inverter in the weak grid, which verify the effectiveness of the parameter design method proposed in this paper.

Keywords: weak grid, dynamic performance, LCL filter, active damping, grid current control

\section{INTRODUCTION}

Currently, distributed power generation systems based on renewable energy have been widely used in power grids (Zhang et al., 2021; Li et al., 2021), and the three-phase grid-connected inverter with an LCL or L filter, as an important interface between the distributed generation system and the grid, plays an important role in it (Busada et al., 2005; Wu and Lehn, 2006; Malinowski and Bernet, 2008; Xin et al., 2017; Xing et al., 2018).

Although the LCL filter has better performance and switching harmonic attenuation ability than the L filter (Lindgren and Svensson, 1998; Hava et al., 1995), the inherent resonance problem of the LCL filter is harmful to the quality of grid current and even affects the stability of the system (Parker and McGrath, 2012). Compared with passive damping solutions proposed in Liserre et al. (2005), Dannehl et al. (2011) that cause non-negligible power loss, the active damping (AD) method is more flexible and efficient. In the literature (Jiao and Lee, 2015), an RLC damping circuit for the LCL filter 
is investigated to solve the resonant frequency peak of an LCL grid-connected inverter, which is equivalent to an $\mathrm{AD}$ control method essentially. The literature (Pena-Alzola et al., 2014) proposes an $\mathrm{AD}$ method by adding a notch filter to the forward channel for canceling the LCL filter resonant peak, but its robustness should be improved, and the parameter adjustment is relatively complex. The literature (Dannehl et al., 2010; Chenlei Bao et al., 2014; Wang et al., 2015) proposes $\mathrm{AD}$ algorithms with three different kinds of feedback signals, which are the filter capacitor current, the filter capacitor voltage, and the grid-side current. In order to decrease power losses caused by multiple sensors and reduce the system cost, the grid-current-feedback AD method is adopted in Xu et al. (2013a), Zhou et al. (2018). Meanwhile, a proportional resonant (PR) controller is preferred to provide suitable power quality to the grid for the inverter, which can significantly increase the gain at the intended frequency, track of the sinusoidal waveform with zero steady-state error, and have better disturbance rejection capability (Holmes et al., 2017; Zmood and Holmes, 2003). According to the method in Liu et al. (2020), a parameter range can be obtained for the $\mathrm{PR}$ controller and $\mathrm{AD}$ loop, which could ensure the grid current quality and system stability under ideal grid conditions.

However, due to the direct interconnection with power grids, system control performance and stability may be affected by weak grid conditions, for example, gird impedance variation (Sun, 2011). It is known that grid impedance can lead to sustained harmonic resonance or other instability problems, which destabilizes the grid-connected inverter (Liserre et al., 2006). Furthermore, the wide-range variation of the grid impedance may affect the resonant suppression for the LCL filter in a weak grid (Liu et al., 2020; Xu et al., 2013b). Therefore, it is necessary to design the control parameters reasonably considering grid impedance in the weak grid.

The existing approaches have been proposed to maintain the grid-connected inverter work normally and stably under weak grid conditions. The literature (Sun, 2011) proposed a method to determine inverter-grid system stability using the inverter output impedance and the grid impedance. It is shown that a gridconnected inverter system will remain stable if the ratio between the grid impedance and the inverter output impedance satisfies the Nyquist stability criterion. Then, based on the impedancebased stability criterion for grid-connected inverters, the literature (Cespedes and Sun, 2014a; Yang et al., 2014; Xu et al., 2018; Zhu et al., 2020) proposed different methods to ensure the stable operation of the grid-connected inverter system in the weak grid. However, this analysis method based on the impedance-based stability criterion needs to design the parameters in advance for the stable operation of the gridconnected inverter system, without considering the grid impedance. Moreover, this method is normally used to analyze the stability of the grid-connected inverter in the weak grid, in which the analysis of the dynamic performance is not considered. In addition, other scholars proposed a control strategy by the grid impedance detection technique to eliminate the impact of the grid impedance on the grid-connected inverter system (Liserre et al., 2007; Cespedes and Sun, 2014b). Although the automatic adaptive control technology based on the grid impedance online measurement can improve the adaptability of the gridconnected inverter system to the weak grid effectively, and the harmonics injected during impedance detection will deteriorate the quality of grid currents. Besides, the control performance of the inverter system depends on the rapidity and accuracy of the grid impedance online measurement, and the dynamic performance of system is still not well addressed.

Above all, under the weak grid, the multi-constrains including stability constraints, resonance suppression constraints, and margin constraints have not been considered to design the current controller and active damping loop comprehensively in these solutions, which determine stability, grid-current quality, and dynamic and steady-state performance of the inverter. Furthermore, considering the variation of grid impedance, the impact of grid impedance on the bandwidth of the inverter system should also be concerned, which also affects the dynamic performance of the system.

In this paper, aiming at improving the dynamic and stability performance of the three-phase LCL-filtered grid-connected inverter with a good quality of the grid current in the weak grid, a parameter design method for the current controller and active damping with grid-side current feedback is proposed in this paper. In Section 2, the mathematical model of the three-phase LCL-filtered grid-connected inverter in the weak grid is established. The influence of the PR controller and the active damping circuit on the resonance peak suppression of the LCL filter and the stability of the inverter under weak grid conditions are analyzed. In Section 3, the parameter constraints of the current controller and active damping loop are analyzed in the weak grid, including stability, resonance suppression, and margin constraints. In Section 4, based on the derived multiconstraints, a parameter design method for the active damping and current controller is proposed, which can achieve the maximum bandwidth of the inverter considering the impedance variation so that the system can operate with a good dynamic and steady-state performance. The experimental results in Section 5 verify the effectiveness of the parameter design method proposed in this paper.

\section{MODELING AND CONTROL OF THE LCL-FILTERED GRID-CONNECTED INVERTER IN THE WEAK GRID}

Figure 1 shows the main circuit of the three-phase LCLfiltered grid-connected inverter under the weak grid. $L_{1 \mathrm{x}}(\mathrm{x}$ $=a, b, c)$ are LCL filter inverter-side three-phase inductors, whose value is $L_{1} . C_{\mathrm{x}}(\mathrm{x}=\mathrm{a}, \mathrm{b}, \mathrm{c})$ are LCL filter three-phase capacitors, whose value is $C_{1} . L_{2 \mathrm{x}}(\mathrm{x}=\mathrm{a}, \mathrm{b}, \mathrm{c})$ are LCL filter gridside three-phase inductors, whose value is $L_{2}$. The weak grid consists of ideal voltage sources $e_{\mathrm{x}}(\mathrm{x}=\mathrm{a}, \mathrm{b}, \mathrm{c})$ and inductive grid impedances $L_{g \mathrm{x}}(\mathrm{x}=\mathrm{a}, \mathrm{b}, \mathrm{c})$, and the value of grid impedance is $L_{g} \cdot u_{i \mathrm{x}}(\mathrm{x}=\mathrm{a}, \mathrm{b}, \mathrm{c})$ are inverter three-phase output voltages, $i_{1 \mathrm{x}}(\mathrm{x}=\mathrm{a}, \mathrm{b}, \mathrm{c})$ are three-phase inverter-side currents of the LCL filter, and $i_{2 \mathrm{x}}(\mathrm{x}=\mathrm{a}, \mathrm{b}, \mathrm{c})$ are three-phase grid-side currents of the filter. $V_{\mathrm{dc}}$ is the dc-bus voltage.

In the two-phase static coordinate system $(\alpha \beta)$, the closed-loop control block diagram of the three-phase LCL-filtered grid- 


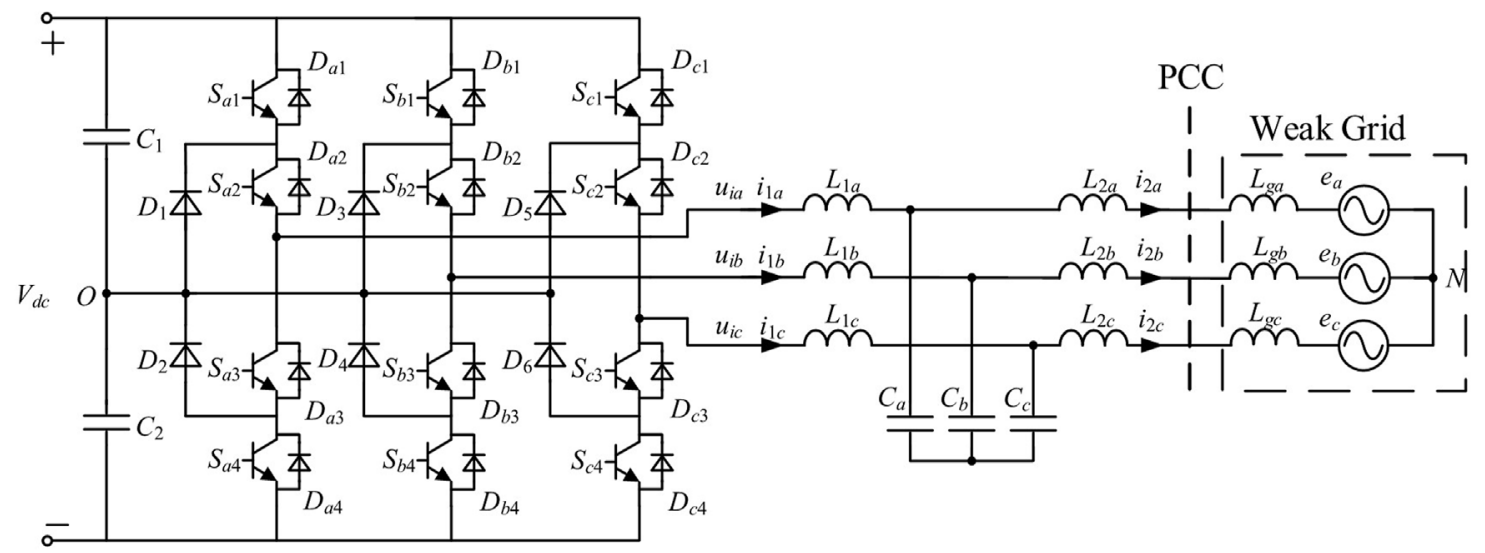

FIGURE 1 | Main circuit diagram of the three-phase LCL-filtered grid-connected inverter.

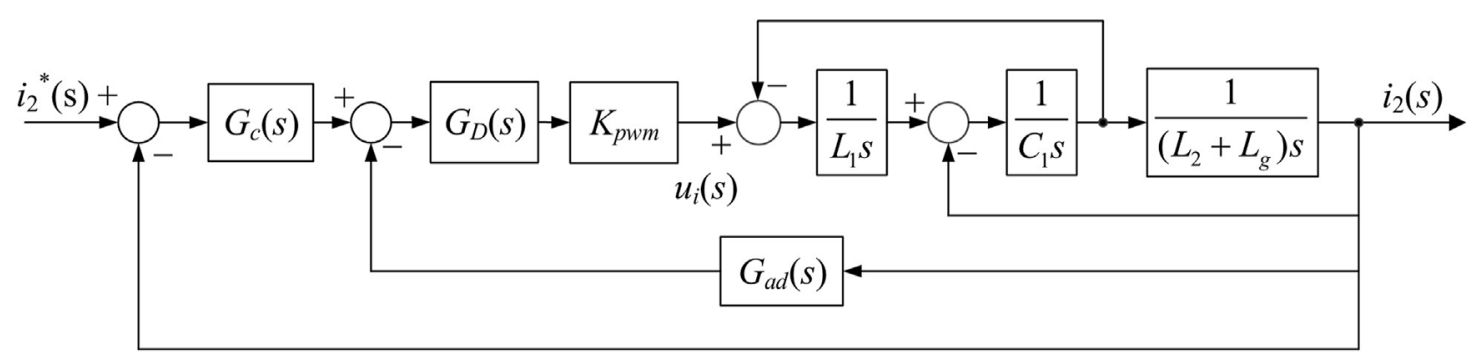

FIGURE 2 | Closed loop control block diagram of the grid-connected inverter in the $\alpha \beta$ coordinate system.

connected inverter is shown in Figure 2, where $K_{\mathrm{pwm}}=V_{\mathrm{dc}} / 2$ is the gain of the PWM inverter. $G_{c}(s)$ is the proportional resonance controller expressed as

$$
G_{c}(s)=K_{p}+K_{r} \frac{2 \omega_{i} s}{s^{2}+2 \omega_{i} s+\omega_{o}^{2}}
$$

where $K_{p}$ and $K_{r}$ are the proportional gain and the resonant gain of the PR controller, $\omega_{i}$ is the cut-off angular frequency of the PR controller, and $\omega_{o}$ is the grid fundamental angular frequency (Chenlei Bao et al., 2014).

$G_{a d}(s)$ is the transfer function of the AD loop. Considering the complexity of the $\mathrm{AD}$ loop which affects the characteristic of three-phase LCL-filtered grid-connected inverter in the lowfrequency range, $G_{a d}(s)$ is implemented by a second-order differential term in the s-domain (Liu et al., 2020). $G_{a d}(s)$ can be expressed as

$$
G_{a d}(s)=k_{a d} \cdot s^{2}
$$

where $k_{a d}$ is the $\mathrm{AD}$ coefficient.

$G_{D}(s)$ is the transfer function of the total delay due to digital control, consisting of the computation delay, the zero-order holder, and the sampling switch. Considering that the computation delay may reduce the control loop bandwidth and make the system unstable, a previously reported time- delay compensator (Lu et al., 2018), as a first-order digital filter with a phase-lead characteristic, is directly adopted to mitigate time delay here. $G_{D}(s)$ is expressed as

$$
G_{D}(s)=\frac{1}{T_{s}} \cdot \frac{1-e^{-s T_{s}}}{s} \approx \frac{1}{1+0.5 s T_{s}}
$$

where $T_{s}$ is the sampling period.

The transfer function from $u_{i}(s)$ to $i_{2}(s)$ for the LCL filter can be derived as

$$
\begin{aligned}
G_{1}(s)=\frac{i_{2}(s)}{u_{i}(s)} & =\frac{1}{C_{1} L_{1}\left(L_{2}+L_{g}\right) s\left(s^{2}+\omega_{r e s}^{2}\right)} \\
\omega_{\text {res }} & =\sqrt{\frac{L_{1}+L_{2}+L_{g}}{C_{1} L_{1}\left(L_{2}+L_{g}\right)}}
\end{aligned}
$$

where $\omega_{\text {res }}$ is defined the resonant frequency when grid impedance $L_{g}$ is considered.

Generally, the resonant gain $K_{r}$ of the PR controller can be neglected at the cutoff frequency $\omega_{c}$ and the frequencies higher than $\omega_{c}$ (Chenlei Bao et al., 2014; Geng et al., 2018). Hence, in the process of analyzing system stability, the current controller $G_{c}(s)$ can be approximated as $K_{p}$. From (1-4), the open-loop transfer function of the system can be derived as 

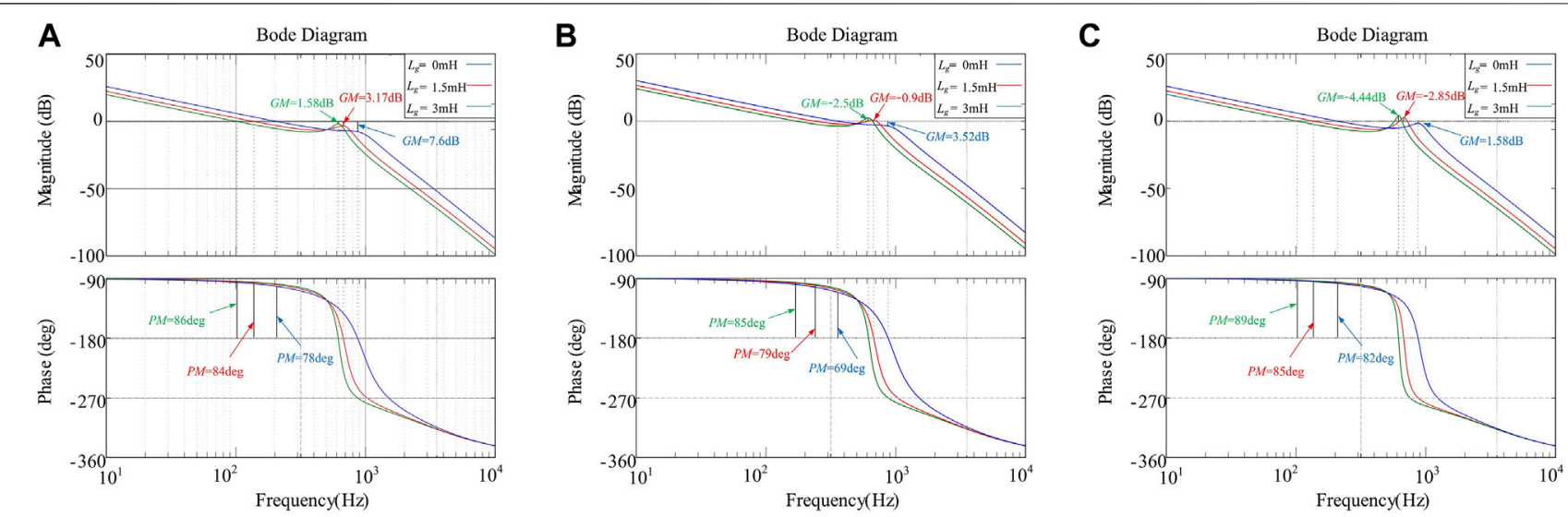

FIGURE 3 | Bode diagram of the system open-loop transfer function. (A) $K_{p}=0.025, k_{a d}=2 \times 10^{-9}$. (B) $K_{p}=0.04, K_{a d}=2 \times 10^{-9}$. (C) $K_{p}=0.025, K_{a d}=1 \times 10^{-9}$.

TABLE 1 | Parameters of the LCL filter.

Parameter

Value

Inverter-side inductor $L_{1}$

Grid-side inductor $L_{2}$

Filter capacitor $C$

Sampling frequency $f_{s}$

$$
G_{o p}(s)=\frac{G_{c}(s) G_{1}(s) K_{\mathrm{PWM}}}{1+0.5 s T_{s}+G_{1}(s) K_{\mathrm{PWM}} k_{a d} s^{2}}
$$

In order to analyze the influence of the PR controller and the active damping loop on the resonance peak suppression of the LCL filter and the stability of the inverter under weak grid conditions, Figure 3 shows the Bode diagram of the openloop transfer function of the system. LCL filter parameters are shown in Table 1, where $f_{s}$ is the sampling frequency.

From Figure 3A, it can be seen that when $K_{p}=0.025$ and $k_{a d}=$ $2 \times 10^{-9}$, the system can maintain stable under different $L_{g}$ conditions. Supposing that $K_{p}$ is modified to 0.04 , as shown in Figure 3B, when $L_{g}$ increases, the gain margin (GM) of the system changes from positive to negative, and the grid-connected inverter becomes unstable. Otherwise, supposing that $k_{a d}$ is modified to $1 \times 10^{-9}$, as shown in Figure 3C, when $L_{g}$ increases, the GM of the system also changes from positive to negative, which means that the grid-connected inverter becomes unstable. Besides, when $L_{g}$ varies, the resonant frequency of the system will shift, which affects the ability of the LCL resonant suppression. Another problem worthy of attention is that the bandwidth of the open-loop transfer function decreases with the increase of $L_{g}$. Taking $L_{g}=3 \mathrm{mH}$ as an example, the bandwidth of the system is close to fundamental frequency, which may not maintain the inverter a good dynamic performance (Dorf and Bishop, 2011).

Above all, both the control parameters and $L_{g}$ affect the ability of the LCL resonant suppression and the performance of the LCL grid-connected inverter. Therefore, in order to ensure the stable operation of the system and improve the dynamic performance under the weak grid, a multi-constrain parameter design method for the active damping loop and current controller considering system bandwidth is proposed in Sections 3, 4 .

\section{CONSTRAINTS OF ACTIVE DAMPING AND THE CURRENT CONTROLLER FOR THE LCL-FILTERED GRID-CONNECTED INVERTER}

\subsection{Stability, Resonance Suppression, and Gain Margin Constraints with the Variation of Grid Impedance}

In order to ensure the effective operation of the LCL gridconnected inverter and make it have better stability and dynamic response performance, the parameters of the current controller and active damping loop for the grid-connected inverter need to meet certain constraints.

Based on (6), by the Routh-Hurwitz criterion, the constrain to ensure the system stability is

$$
0<K_{\mathrm{p}}<K_{\mathrm{p} 1}\left(k_{a d}, L_{g}\right)
$$

where

$$
K_{\mathrm{p} 1}\left(k_{a d}, L_{g}\right)=\frac{k_{a d}\left(L_{1}+L_{2}+L_{g}\right)}{C_{1} L_{1}\left(L_{2}+L_{g}\right)}
$$

Due to the existence of the delay $G_{D}(s)$, the resonant frequency $\omega_{\text {res }}$ of the LCL filter will shift after adding the active damping control loop, note that as $\omega_{\text {res }}$. Figure $\mathbf{4}$ can be obtained by equivalent transformation of Figure 2. With this representation, it immediately informs that a virtual impedance $Z_{\mathrm{eq}}$ in parallel with filter capacitor $C_{1}$ is introduced by the $\mathrm{AD}$ control loop. $Z_{\mathrm{eq}}$ can be expressed as

$$
Z_{\mathrm{eq}}(s)=\frac{L_{1}\left(L_{2}+L_{g}\right)\left(1+0.5 s T_{s}\right)}{K_{\mathrm{PWM}} k_{a d}}
$$




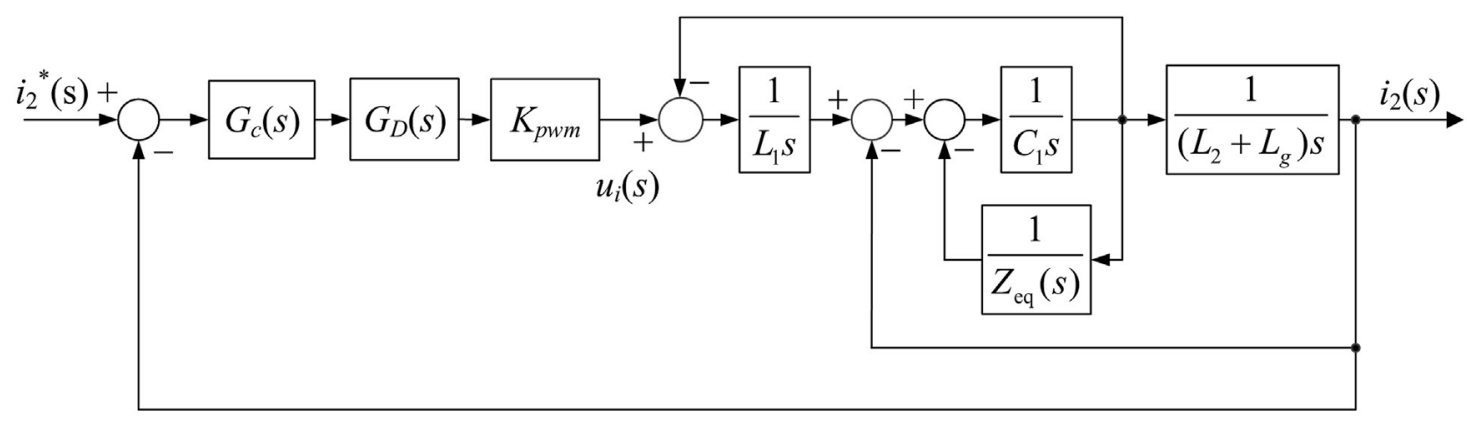

FIGURE 4 | Equivalent closed loop control block diagram of the grid-connected inverter in the $\alpha \beta$ coordinate system.

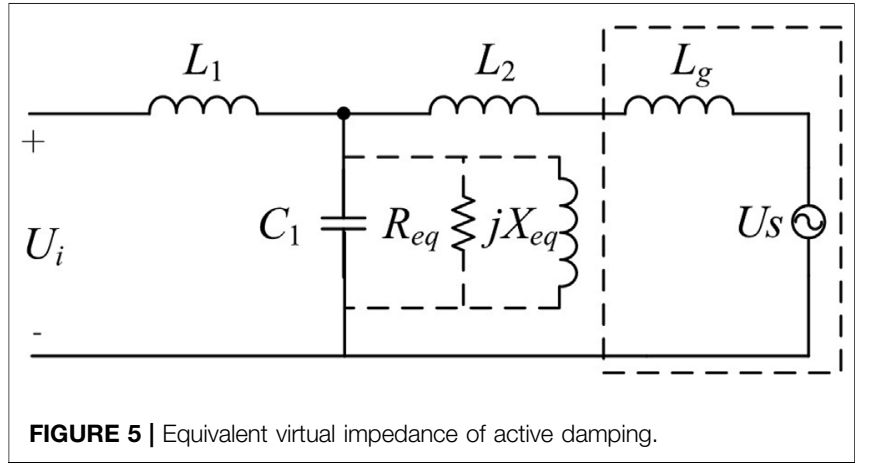

Figure 5 shows the equivalent physical circuit of the LCL filter, where $Z_{\mathrm{eq}}=R_{\mathrm{eq}} / / X_{\mathrm{eq}}$. Substitute $s=j \omega$ into (9), the expressions of $R_{\mathrm{eq}}$ and $X_{\mathrm{eq}}$ are given in (10)

$$
\begin{aligned}
& R_{\mathrm{eq}}=\frac{L_{1}\left(L_{2}+L_{g}\right)\left(1+0.25 \omega^{2} T_{s}^{2}\right)}{K_{\mathrm{PWM}} k_{a d}} \\
& X_{\mathrm{eq}}=\frac{L_{1}\left(L_{2}+L_{g}\right)\left(1+0.25 \omega^{2} T_{s}^{2}\right)}{0.5 \omega T_{s} K_{\mathrm{PWM}} k_{a d}}
\end{aligned}
$$

From Figure 5, the expression of $\omega_{\text {res }}{ }^{\prime}$ of the system after adding active damping is

$$
\omega_{\text {res }}{ }^{\prime}=\sqrt{\frac{2 k_{a d} K_{\mathrm{PWM}} T_{s}-4 C_{1} L_{1}\left(L_{2}+L_{g}\right)+\left(L_{1}+L_{2}+L_{g}\right) T_{s}^{2}+\sqrt{A}}{2 T_{s}^{2} C_{1} L_{1}\left(L_{2}+L_{g}\right)}}
$$

where

$$
\begin{aligned}
A= & 16 C_{1} L_{1}\left(L_{2}+L_{g}\right)\left(L_{1}+L_{2}+L_{g}\right) T_{s}^{2} \\
& +\left(4 C_{1} L_{1}\left(L_{2}+L_{g}\right)-2 k_{a d} K_{\mathrm{PWM}} T_{s}-\left(L_{1}+L_{2}+L_{g}\right) T_{s}^{2}\right)^{2}
\end{aligned}
$$

Generally, the gain of $G_{o p}(s=j \omega)$ should be less than $0 \mathrm{~dB}$ at $\omega_{\text {res }}$ ', which maintains the suppression ability for the resonant peak. Through making $20 \lg \left|G_{o p}\left(s=j \omega_{\text {res }}{ }^{\prime}\right)\right| \leq 0, K_{p}$ can be derived as

$$
K_{\mathrm{p}}<K_{\mathrm{p} 2}\left(k_{a d}, L_{g}\right)
$$

where

$$
\begin{aligned}
& K_{p 2}\left(k_{a d}, L_{g}\right)=\frac{\sqrt{x^{2}+y^{2}}}{K_{\mathrm{PWM}}} \\
& x=0.5 C_{1} L_{1}\left(L_{2}+L_{g}\right) T_{s} \omega_{\text {res }}{ }^{4}-\left(0.5\left(L_{1}+L_{2}+L_{g}\right) T_{s}+k_{a d} K_{\mathrm{PWM}}\right) \omega_{\text {res }}{ }^{2} \\
& y=\left(L_{1}+L_{2}+L_{g}\right) \omega_{\text {res }}{ }^{\prime}-C_{1} L_{1}\left(L_{2}+L_{g}\right) \omega_{\text {res }}{ }^{3}
\end{aligned}
$$

Considering the phase of $G_{o p}(s=j \omega)$ is $-180^{\circ}$ at crossing frequency $\omega_{h}, G_{o p}(s=j \omega)$ is absolutely real at $\omega_{h}$. Making $\operatorname{Im}\left(G_{o p}\right.$ $(s=j \omega))=0$, the expression of $\omega_{h}$ can be obtained as

$$
\omega_{h}=\sqrt{\frac{L_{1}+L_{2}+L_{g}}{C_{1} L_{1}\left(L_{2}+L_{g}\right)}}
$$

The grid-connected inverter system needs to have a certain gain margin (GM) to ensure sufficient stability. We assume that the ideal gain margin is $\mathrm{GM}_{0}$ at $\omega_{h}$, which is generally $3 \mathrm{~dB}$ (Guan et al., 2019). In order to ensure $\mathrm{GM} \geq \mathrm{GM}_{0}$, the gain margin constraint of $K_{p}$ is

$$
K_{\mathrm{p}} \leq K_{\mathrm{p} 3}\left(k_{a d}, L_{g}\right)
$$

where

$$
K_{\mathrm{p} 3}\left(k_{a d}, L_{g}\right)=\frac{k_{a d}\left(L_{1}+L_{2}+L_{g}\right)}{C_{1} L_{1}\left(L_{2}+L_{g}\right)} \cdot 10^{-\frac{\mathrm{GM}_{0}}{20}}
$$

In Etxegarai et al. (2012), the maximum value of the grid impedance $L_{g}$ is expressed as

$$
L_{g_{-} \max }=\frac{U_{s}}{\omega_{o} I_{N} \cdot \mathrm{SCR}}
$$

where $U_{s}$ is the root mean square of grid-connected voltage and $I_{N}$ is the root mean square of grid-connected current.

When the grid inductance $L_{g}$ is in the range $\left[0, L_{g_{-} \max }\right]$, in order to ensure that $K_{p}$ simultaneously satisfies the three constraints in $(7,13,16), K_{p}$ needs to be less than or equal to the minimum among them as 


$$
\begin{aligned}
K_{p} \leq \min \left\{K_{\mathrm{p} 1}\left(k_{a d}, L_{g}\right), K_{\mathrm{p} 2}\left(k_{a d}, L_{g}\right), K_{\mathrm{p} 3}\left(k_{a d}, L_{g}\right)\right. \\
\left.\quad \mid 0 \leq L_{g} \leq L_{g_{-} \max }\right\}
\end{aligned}
$$

which is

$$
K_{p} \leq K_{\mathrm{p} 3}\left(k_{a d}, L_{g_{-} \max }\right)
$$

\subsection{Phase Margin Constraint With the Variation of Grid Impedance}

In addition, the system also needs to meet the phase margin (PM) requirement for good stability and dynamic performance, and the expression of PM is

$$
\begin{aligned}
\mathrm{PM} & =180^{\circ}+\angle G_{o p}\left(s=j \omega_{c}\right) \\
& =180^{\circ}+\arctan \frac{\omega_{c}{ }^{2}-\omega_{\text {res }}{ }^{2}}{0.5 T_{s} \omega_{c}{ }^{3}-0.5 T_{s} \omega_{c} \omega_{r e s}{ }^{2}-\frac{k_{a d} K_{P W M} \omega_{c}}{C_{1} L_{1}\left(L_{2}+L_{g}\right)}}
\end{aligned}
$$

Then, the AD coefficient $k_{a d}$ can be expressed as

$$
\begin{aligned}
k_{a d}= & \frac{0.5 C_{1} L_{1}\left(L_{2}+L_{g}\right) T_{s} \omega_{c}^{2}-0.5\left(L_{1}+L_{2}+L_{g}\right) T_{s}}{K_{\mathrm{PWM}}} \\
& +\frac{\omega_{r e s}^{2}-\omega_{c}^{2}}{K_{\mathrm{PWM}} \omega_{c} \tan (\mathrm{PM})}
\end{aligned}
$$

Furthermore, the partial differential of $k_{a d}$ with respect to $\mathrm{PM}$ is

$$
\frac{\partial k_{a d}}{\partial \mathrm{PM}}=\frac{\omega_{r e s}^{2}-\omega_{c}^{2}}{K_{\mathrm{PWM}} \omega_{c}}\left(-\frac{1}{\sin ^{2} \mathrm{PM}}\right)
$$

In order to make the system parameter design reasonable, the cut-off frequency $\omega_{c}$ should be smaller than $\omega_{\text {res }}$. From (23), the active damping parameter $k_{a d}$ and the phase margin PM are in a monotonically decreasing relationship.

We assuming that the ideal phase margin is $\mathrm{PM}_{0}$, which is generally $45^{\circ}$. In order to ensure $\mathrm{PM} \geq \mathrm{PM}_{0}$, combining (22) with (23), $k_{a d}$ needs to meet

$$
k_{a d} \leq k_{a d}{ }^{\prime}\left(L_{g}, \omega_{c}\right)
$$

where

$$
\begin{aligned}
k_{a d}{ }^{\prime}\left(L_{g}, \omega_{c}\right) & =\frac{0.5 C_{1} L_{1}\left(L_{2}+L_{g}\right) T_{s} \omega_{c}^{2}-0.5\left(L_{1}+L_{2}+L_{g}\right) T_{s}}{K_{\mathrm{PWM}}} \\
& +\frac{\omega_{r e c}^{2}-\omega_{c}^{2}}{K_{\mathrm{PWM}} \omega_{c} \tan \left(\mathrm{PM}_{0}\right)}
\end{aligned}
$$

The partial derivative of $k_{a d}{ }^{\prime}\left(L_{g}, \omega_{c}\right)$ with respect to $L_{g}$ in (25) can be obtained

$$
\left\{\begin{array}{l}
\frac{\partial k_{a d}{ }^{\prime}\left(L_{g}, \omega_{c}\right)}{\partial L_{g}} \geq 0, \omega_{o}<\omega_{c} \leq \frac{1}{\sqrt{C_{1} L_{1}}} \\
\frac{\partial k_{a d}{ }^{\prime}\left(L_{g}, \omega_{c}\right)}{\partial L_{g}}<0, \frac{1}{\sqrt{C_{1} L_{1}}}<\omega_{c}<\omega_{r e s}{ }^{\prime}
\end{array}\right.
$$

According to (26), when $1 / \sqrt{C_{1} L_{1}}<\omega_{c}<\omega_{\text {res }}{ }^{\prime}, k_{a d}{ }^{\prime}\left(L_{g}, \omega_{c}\right)$ decreases monotonously with respect to $L_{g}$; when $\omega_{\mathrm{o}}<\omega_{c} \leq$ $1 / \sqrt{C_{1} L_{1}}, k_{a d}{ }^{\prime}\left(L_{g}, \omega_{c}\right)$ increases monotonously with respect to $L_{g}$. To make the phase margin of the system meet the requirements when $L_{g}$ is in the range $\left[0, L_{g \_ \text {max }}\right], k_{a d}$ needs to meet the following requirements:

$$
\left\{\begin{array}{l}
k_{a d} \leq k_{a d}{ }^{\prime}\left(0, \omega_{c}\right), \omega_{o}<\omega_{c} \leq \frac{1}{\sqrt{C_{1} L_{1}}} \\
k_{a d} \leq k_{a d}{ }^{\prime}\left(L_{g_{-} \max }, \omega_{c}\right), \frac{1}{\sqrt{C_{1} L_{1}}}<\omega_{c}<\omega_{\text {res }}{ }^{\prime}
\end{array}\right.
$$

Above all, the stability, resonance suppression, gain margin, and phase margin constraints with the variation of grid impedance are derived, ensuring that the system has a good performance while suppressing LCL resonance. Besides, under the weak grid, according to $7, \mathbf{1 3}, \mathbf{1 6}$, and 25 , the range of $K_{p}$ is affected by $k_{a d}$ and $L_{g}$, and the range of $k_{a d}$ is affected by $\omega_{c}$ and $L_{g}$. Considering the grid impedance $L_{g}$, the control parameters $K_{p}$ and $k_{a d}$ can be determined according to the requirements of the system for $\omega_{c}$ which determines the bandwidth of the system.

\section{PARAMETER DESIGN FOR ACTIVE DAMPING AND THE CURRENT CONTROLLER OF THE LCL-FILTERED GRID-CONNECTED INVERTER}

In order to maintain the grid-connected inverter, a good dynamic performance with the stability, resonance suppression, and gain margin and phase margin constraints in the weak grid, the bandwidth $\left(\omega_{c}\right)$ of the system should be set to the maximal value considering the variation of the grid impedance.

According to the two cases in (27), $K_{p}$ of the current controller and $k_{a d}$ of the active damping loop are analyzed and solved at different $\omega c$ ranges.

\subsection{Case I: $1 / \sqrt{C_{1} L_{1}}<\omega_{c}<\omega_{\text {res }}{ }^{\prime}$}

From (27), in this case, if the phase margin of the system meets the requirements when $L_{g}$ is in the range $\left[0, L_{g \_ \text {max }}\right], k_{a d}$ needs to meet

$$
k_{a d} \leq k_{a d 11}\left(\omega_{c}\right)
$$

where

$$
k_{a d 11}\left(\omega_{c}\right)=k_{a d}\left(L_{g_{-} \max }, \omega_{c}\right)
$$

At $\omega_{c}$, the gain of the system open-loop transfer function equals to 1 . By making $\left|G_{o p}\left(s=j \omega_{c}\right)\right|=1, K_{p}$ can be expressed as

$$
K_{p}\left(k_{a d}, L_{g}, \omega_{c}\right)=\frac{\sqrt{m^{2}+n^{2}}}{K_{\mathrm{PWM}}}
$$

where

$$
\begin{aligned}
m & =0.5 C_{1} L_{1}\left(L_{2}+L_{g}\right) T_{s} \omega_{c}^{4}-\left(0.5\left(L_{1}+L_{2}+L_{g}\right) T_{s}+k_{a d} K_{\mathrm{PWM}}\right) \omega_{c}^{2} \\
n & =\left(L_{1}+L_{2}+L_{g}\right) \omega_{c}-C_{1} L_{1}\left(L_{2}+L_{g}\right) \omega_{c}^{3}
\end{aligned}
$$


and then when $L_{\mathrm{g}}=L_{\mathrm{g} \_ \text {max }}, K_{\mathrm{p}}=K_{\mathrm{p}}\left(k_{a d}, L_{g_{-} \max }, \omega_{c}\right), K_{p}$ should also meet the constraint in (20) as

$$
\left\{\begin{array}{l}
K_{\mathrm{p}}=K_{\mathrm{p}}\left(k_{a d}, L_{g_{-} \max }, \omega_{c}\right) \\
K_{\mathrm{p}} \leq K_{\mathrm{p} 3}\left(k_{a d}, L_{g_{-} \max }\right)
\end{array}\right.
$$

By solving (32), $k_{a d}$ also needs to meet

$$
k_{a d} \geq k_{a d 12}\left(\omega_{c}\right) \omega_{c}<\sqrt[4]{10^{-0.1 \mathrm{GM}}} \omega_{\text {res }}{ }^{\prime}
$$

where

$$
\begin{aligned}
& k_{a d 12}\left(\omega_{c}\right)=0.5 C_{1} L_{1}\left(L_{2}+L_{g_{-} \max }\right)^{2}\left(C_{1} L_{1} L_{2} \omega_{c}^{2}-L_{1}-L_{2}-L_{g_{-} \max }\right) \\
& \cdot \frac{\left(C_{1} L_{1}\left(L_{2}+L_{g_{-} \max }\right) \omega_{c}^{3}+\sqrt{B}\right) \omega_{c}}{\left(C_{1}^{2} L_{1}^{2}\left(L_{2}+L_{g_{-} \max }\right)^{2} \omega_{c}^{4}-10^{-0.1 G M}\left(L_{1}+L_{2}+L_{g_{-} \max }\right)^{2}\right) K_{\mathrm{PWM}}} \\
& B=-4 C_{1}^{2} L_{1}^{2}\left(L_{2}+L_{g_{-} \max }\right)^{2} \omega_{c}^{4}+10^{-0.1 G M}\left(L_{1}+L_{2}+L_{g_{-} \max }\right)^{2} T_{s}^{2} \omega_{c}^{2} \\
& +4 \cdot 10^{-0.1 G M}\left(L_{1}+L_{2}+L_{g_{-} \max }\right)^{2}
\end{aligned}
$$

Substituting system parameters into $(\mathbf{2 8}, \mathbf{3 3})$, when $1 / \sqrt{C_{1} L_{1}}$ $<\omega_{c}<\omega_{\text {res }}{ }^{\prime}$, we get

$$
k_{a d 12}\left(\omega_{c}\right)>k_{a d 11}\left(\omega_{c}\right)
$$

Therefore, in this case, the active damping parameter $k_{a d}$ that satisfies all constraints cannot be obtained.

\subsection{Case II: $\omega_{0}<\omega_{c}<1 / \sqrt{C_{1} L_{1}}$}

Similar to the analysis in case $I$, if the phase margin of the system meets the requirements when $L_{g}$ is in the range $\left[0, L_{g_{-} \max }\right], k_{a d}$ needs to meet

$$
k_{a d} \leq k_{a d 21}\left(\omega_{c}\right)
$$

where

$$
k_{a d 21}\left(\omega_{c}\right)=k_{a d}^{\prime}\left(0, \omega_{c}\right)
$$

and then when $L_{\mathrm{g}}=0, K_{\mathrm{p}}=K_{\mathrm{p}}\left(k_{a d}, 0, \omega_{c}\right), K_{p}$ should also meet the constraint in (20) as

$$
\left\{\begin{array}{l}
K_{\mathrm{p}}=K_{\mathrm{p}}\left(k_{a d}, 0, \omega_{c}\right) \\
K_{\mathrm{p}} \leq K_{\mathrm{p} 3}\left(k_{a d}, L_{g_{-} \max }\right)
\end{array}\right.
$$

By solving (38), $k_{a d}$ also needs to meet

$$
k_{a d} \geq k_{a d 22}\left(\omega_{c}\right)
$$

where

$$
\begin{gathered}
k_{a d 22}\left(\omega_{c}\right)=0.5 C_{1} L_{1}\left(L_{2}+L_{g_{-} \max }\right)^{2}\left(C_{1} L_{1} L_{2} \omega_{c}^{2}-L_{1}-L_{2}\right) \\
\cdot \frac{\left(C_{1} L_{1}\left(L_{2}+L_{g_{-} \max }\right) \omega_{c}^{3}+\sqrt{B}\right) \omega_{c}}{\left(C_{1}^{2} L_{1}^{2}\left(L_{2}+L_{g_{-} \max }\right)^{2} \omega_{c}^{4}-10^{-0.1 G M}\left(L_{1}+L_{2}+L_{g_{-} \max }\right)^{2}\right) K_{\mathrm{PWM}}}
\end{gathered}
$$

Combining (37) with (40), the partial derivative of $k_{a d 21}$ $\left(\omega_{c}\right)$ and $k_{a d 22}\left(\omega_{c}\right)$ with respect to $L_{g}$ in $(25)$ can be obtained
TABLE 2 | Parameters of the LCL grid-connected inverter.

\begin{tabular}{lc} 
Parameter & Value \\
\hline Inverter-side inductor $L_{1}$ & $2 \mathrm{mH}$ \\
Grid-side inductor $L_{2}$ & $1 \mathrm{mH}$ \\
Filter capacitor $C$ & $50 \mu \mathrm{F}$ \\
DC-side Voltage $V_{d c}$ & $300 \mathrm{~V}$ \\
Grid Voltage $U_{s}$ & $77 \mathrm{~V}(\mathrm{rms})$ \\
Rated Power $P$ & $2 \mathrm{~kW}$ \\
Sampling frequency $f_{s}$ & $10 \mathrm{kHz}$
\end{tabular}

$$
\left\{\begin{array}{l}
\frac{\partial k_{a d 21}\left(\omega_{c}\right)}{\partial \omega_{c}}<0 \\
\frac{\partial k_{a d 22}\left(\omega_{c}\right)}{\partial \omega_{c}}>0
\end{array}\right.
$$

It can be seen from (41) that $k_{a d 21}\left(\omega_{c}\right)$ decreases monotonously with respect to $\omega_{c}$, and $k_{a d 22}\left(\omega_{c}\right)$ increases monotonously with respect to $\omega_{c}$. By solving $k_{a d 21}\left(\omega_{c}\right)=k_{a d 22}$ $\left(\omega_{c}\right)$, the expressions of optimal active damping parameter $k_{a d \_o p t}$ and optimal proportional gain $K_{p_{-} o p t}$ can be derived as

$$
\left\{\begin{aligned}
k_{a d_{-} \mathrm{opt}} & =\frac{0.5 C_{1} L_{1} L_{2} T_{s} \omega_{c_{-} \max }^{2}-0.5\left(L_{1}+L_{2}\right) T_{s}}{K_{\mathrm{PWM}}} \\
& +\frac{L_{1}+L_{2}-C_{1} L_{1} L_{2} \omega_{c_{-} \text {max }}^{2}}{K_{\mathrm{PWM}} \omega_{c_{-} \max } \tan (P M)} \\
K_{\mathrm{p}_{\text {opt }}} & =\frac{k_{a d_{-} \text {opt }}\left(L_{1}+L_{2}+L_{g_{-} \max }\right)}{C_{1} L_{1}\left(L_{2}+L_{g_{-} \max }\right)} \cdot 10^{-\frac{G M}{20}}
\end{aligned}\right.
$$

According to $(\mathbf{1 8}, \mathbf{4 2})$ and system parameters in Table 2, the values of $k_{a d \_o p t}$ and $K_{p \_o p t}$ are respectively

$$
\left\{\begin{array}{l}
k_{\text {ad_opt }}=5 \times 10^{-9} \\
K_{\text {p_opt }}=0.05
\end{array}\right.
$$

Therefore, to maintain the system a good dynamic performance in the weak grid, considering the maximal bandwidth of the system in the weak grid, the optimal $K_{p}$ and $k_{a d}$ are derived from the stability, resonance suppression, and gain margin and phase margin constraints.

In order to realize digital control, it is necessary to discretize each part of the grid-connected inverter control system. Applying the $\mathrm{ZOH} z$-transformation, the transfer function of the LCL filter in (4) can be given by

$$
G_{1}(z)=\frac{\omega_{\text {res }} T_{s}\left(z^{2}-2 z \cos \omega_{\text {res }} T_{s}+1\right)-(z-1)^{2} \sin \omega_{\text {res }} T_{s}}{\omega_{\text {res }}\left(L_{1}+L_{2}+L_{g}\right)(z-1)\left(z^{2}-2 z \cos \omega_{\text {res }} T_{s}+1\right)}
$$

By the Tustin method with pre-warping, the transfer function of the PR controller in (1) can be transformed to $G_{c}(z)$, which can be derived as

$$
G_{c}(z)=K_{p}+K_{r} \frac{\omega_{i} \sin \left(\omega_{o} T_{s}\right)\left(z^{2}-1\right)}{\omega_{o}\left(z^{2}-2 z \cos \omega_{o} T_{s}+1\right)+\omega_{i} \sin \left(\omega_{o} T_{s}\right)\left(z^{2}-1\right)}
$$




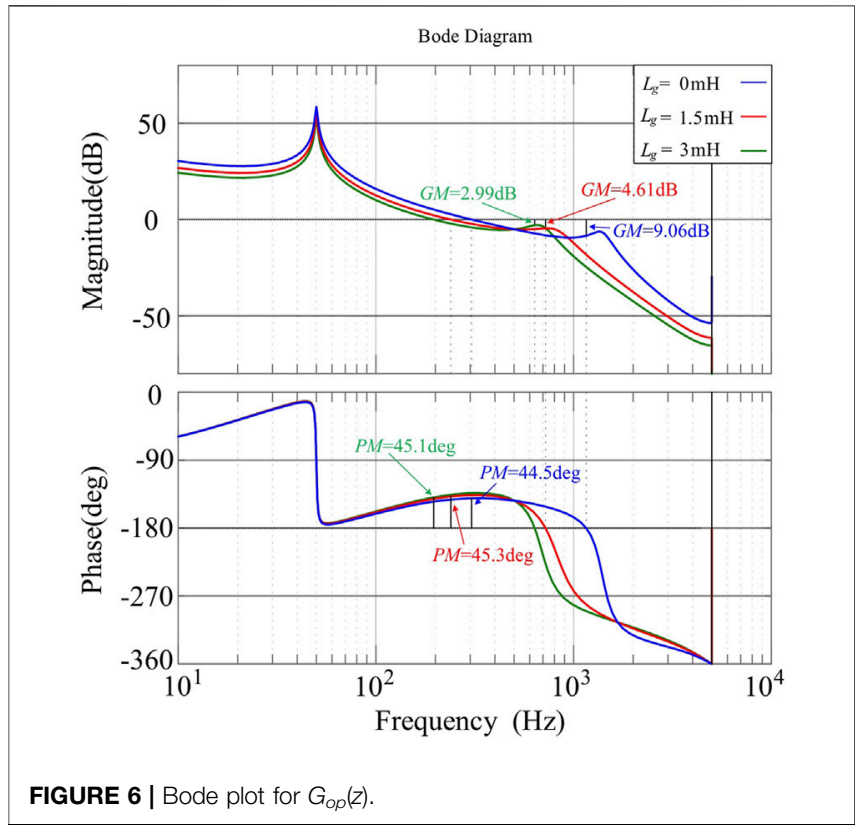

$G_{a d}(z)$ is the transfer function of the $\mathrm{AD}$ loop in the $z$-domain, by applying the backward-difference transformation to (2), $G_{a d}(z)$ can be described as

$$
G_{a d}(z)=\frac{k_{a d}(z-1)^{2}}{T_{s}^{2} z^{2}}
$$

The expression of the open-loop transfer function of the LCL grid-connected inverter after discretization is

$$
G_{\mathrm{op}}(z)=G_{c}(z) \cdot \frac{K_{\mathrm{pwm}} G_{1}(z)}{1+K_{\mathrm{pwm}} G_{1}(z) G_{a d}(z)}
$$

Based on (43) and system parameters in Table 2, Figure 6 shows the Bode plot for $G_{o p}(z)$ with $L_{g}$ variation. It can be seen that the system can remain stable and have a sufficient margin and the bandwidth of the system is relatively large. When $L_{g}=$ $0 \mathrm{mH}, L_{g}=1.5 \mathrm{mH}$, and $L_{g}=3 \mathrm{mH}$, the bandwidths of the system are 320,250 , and $205 \mathrm{~Hz}$, respectively.

Compared with Figure 3, when the optimal parameters $K_{p}$ and $k_{a d}$ in (43) are applied considering the variation of $L_{g}$, not only can the constraint conditions in Section 3 be met to ensure the stable operation of the inverter but also a large bandwidth can be obtained to improve the dynamic performance.

\section{EXPERIMENTAL RESULTS}

To verify the effectiveness of the parameter design method proposed in this paper under the weak grid, an experimental prototype of the three-phase LCL-filtered grid-connected inverter is built. The parameters of the experimental prototype are listed in Table 2 . In the experimental platform, as shown in Figure 7A, a digital control system consists of a TMS320F28335 DSP and a EPM1270T CPLD. The DSP is

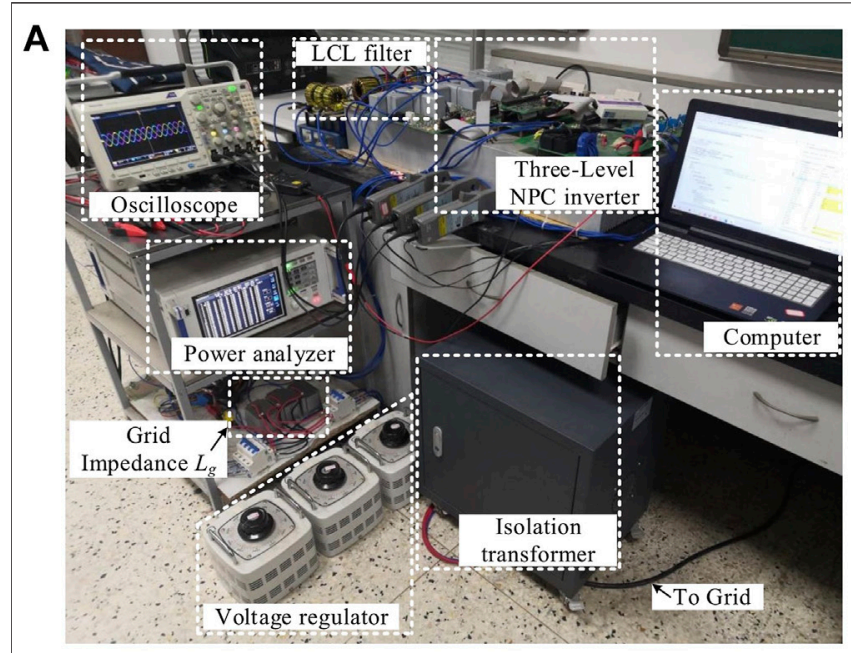

B

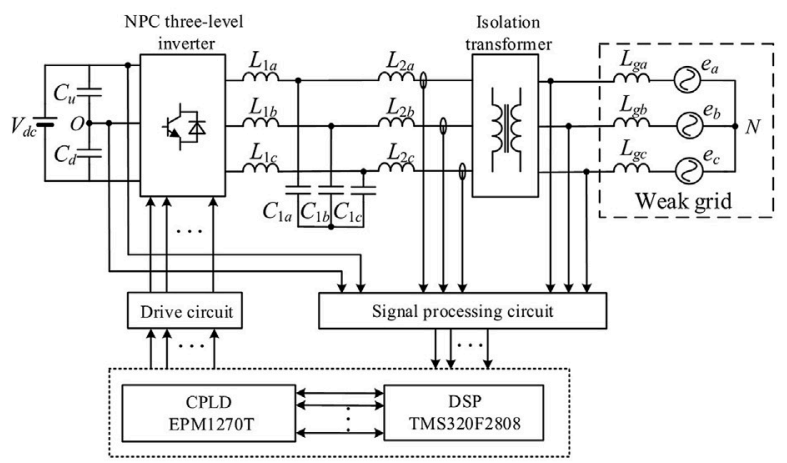

FIGURE 7 | Schematic diagram and experimental photograph of the system. (A) Schematic diagram of the system. (B) Experimental photograph of the system.

applied for the implementation of the control algorithm mainly, which also completes the sampling of grid phase voltages and grid phase currents. Besides, the CPLD is used to arrange digital signals and realize protections for power switches. The photograph of the experimental platform is shown in Figure $\mathbf{7 B}$, where the oscilloscope and power analyzer are Tektronix MDO3000 and HIOKI PW6001, respectively. By applying the proposed method and the methods in Jiao and Lee (2015) and Liu et al. (2020), comparisons of the experimental results are shown in Figures 8-13.

Figures 8-10 $\left(L_{g}=0 \mathrm{mH}, L_{g}=1.5 \mathrm{mH}\right.$, and $L_{g}=3 \mathrm{mH}$, respectively) show the steady-state experimental waveforms of the inverter against different grid impedances with the three methods, in which $i_{\mathrm{a}}, i_{\mathrm{b}}$, and $i_{\mathrm{c}}$ are the three-phase grid currents and $v_{\text {pcca }}$ is the PCC voltage of phase A. It can be seen that when the grid impedance varies, the proposed method can achieve a better quality of grid currents for the inverter, and the THD of grid currents are $1.41,1.66$, and $1.63 \%$, respectively, which satisfy the harmonic distortion standard (IEEE Recommended Practice and Requirements for Harmonic Control in Electric Power Systems, 2014) (IEEE Std. 519-2014) for the grid currents of 

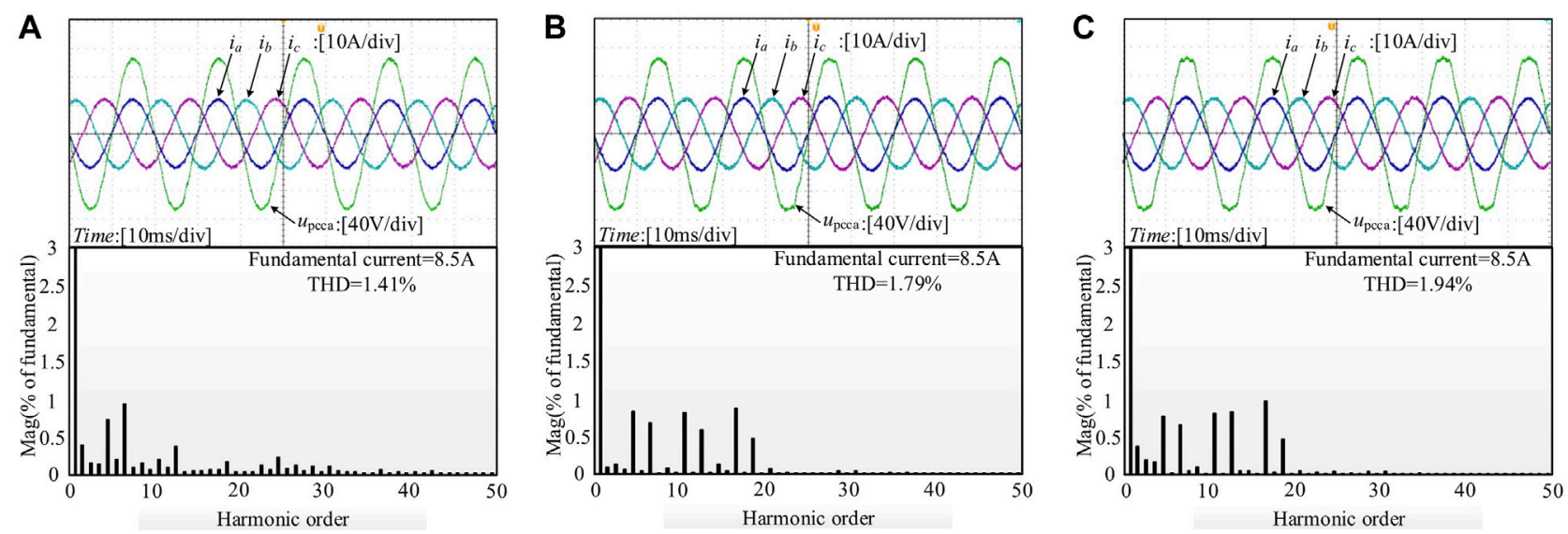

FIGURE 8 | Steady-state experimental waveforms of the inverter at $L_{g}=0 \mathrm{mH}$ : (A) with the proposed method in this paper, (B) with the method in Liu et al. (2020), and (C) with the method in Jiao and Lee (2015).
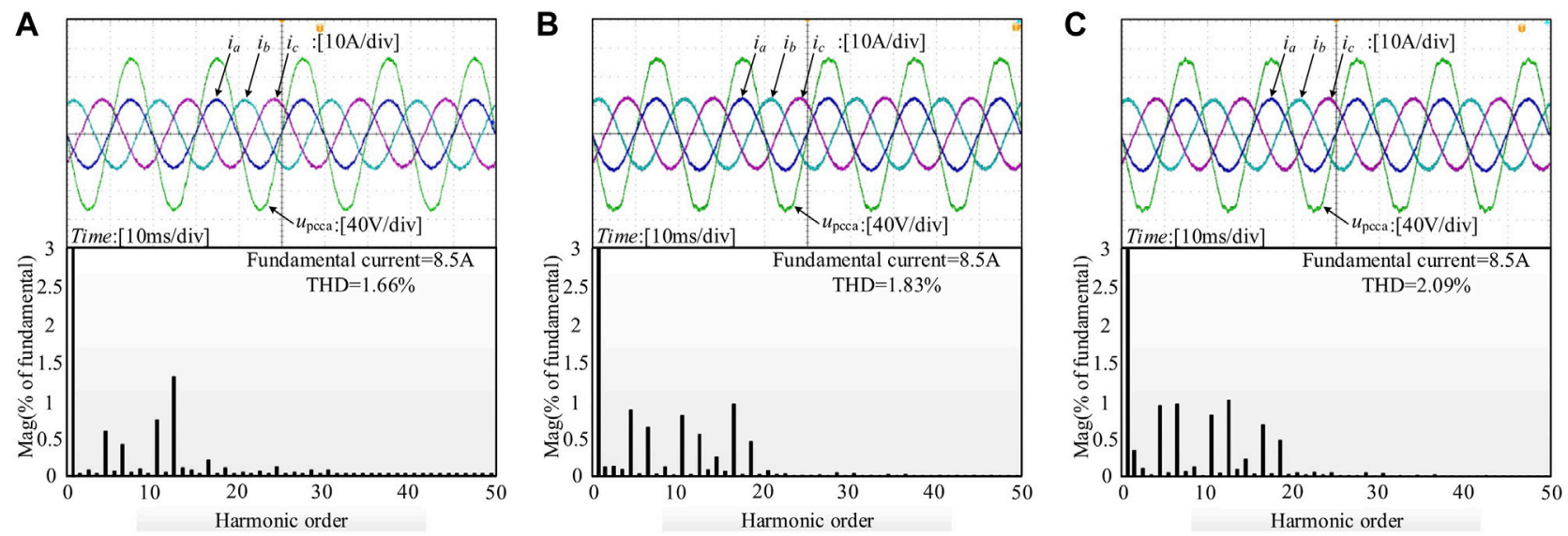

FIGURE 9|Steady-state experimental waveforms of the inverter at $L_{g}=1.5 \mathrm{mH}$ : (A) with the proposed method in this paper, (B) with the method in Liu et al. (2020), and (C) with the method in Jiao and Lee (2015).

the inverter. In addition, the THD result with the proposed method is lower than that with other two methods in Jiao and Lee (2015) and Liu et al. (2020) obviously.

Moreover, according to the THD results of the grid current, compared with other two methods in Ref Jiao and Lee (2015) and Liu et al. (2020), when the proposed method is applied, the resonance peak (at $850 \mathrm{~Hz}$ in Figure 8, $750 \mathrm{~Hz}$ in Figure 9, and $650 \mathrm{~Hz}$ in Figure 10) around the LCL resonant frequency is suppressed more effectively under different grid impedance conditions, especially when $L_{g}$ is $3 \mathrm{mH}$ in Figure $\mathbf{1 0}$.

Furthermore, to demonstrate the advantage of the proposed method against different grid impedances, Figures 11-13 show the dynamic experimental waveforms of the inverter with the three methods when the current reference steps from half to full loads. In Figures 11A, 12A, 13A, supposing that $L_{g}$ varies from 0 to $3 \mathrm{mH}(0,1.5$, and $3 \mathrm{mH})$, the adjustment time $\Delta t$ is 20,23 , and $31 \mathrm{~ms}$, respectively, with the proposed method in this paper. The adjustment time with the other two methods in Jiao and Lee
(2015) and Liu et al. (2020) is listed in Table 3, which shows the comparisons of the dynamic adjustment time with the three methods above. It can be seen that although the gridconnected inverter system can operate stably with the above three methods, the proposed method in this paper has a shorter adjustment time that is less than a fundamental frequency period against different grid impedances among the three methods.

Above all, according to comparisons of experimental results with the three methods against different grid impedances, the proposed method can obtain the optimal proportional gain $K_{p}$ of the PR controller and the AD coefficient $k_{a d}$ of the AD loop for the LCL-filtered grid-connected inverter system, which maintains that the inverter system achieves better grid current quality, and the resonance peak of the LCL filter is suppressed more effectively under weak grid conditions. Besides, the experimental results show that the dynamic adjustment time of the proposed method is shortened obviously, which illustrates a better dynamic performance of the grid-connected inverter system. 

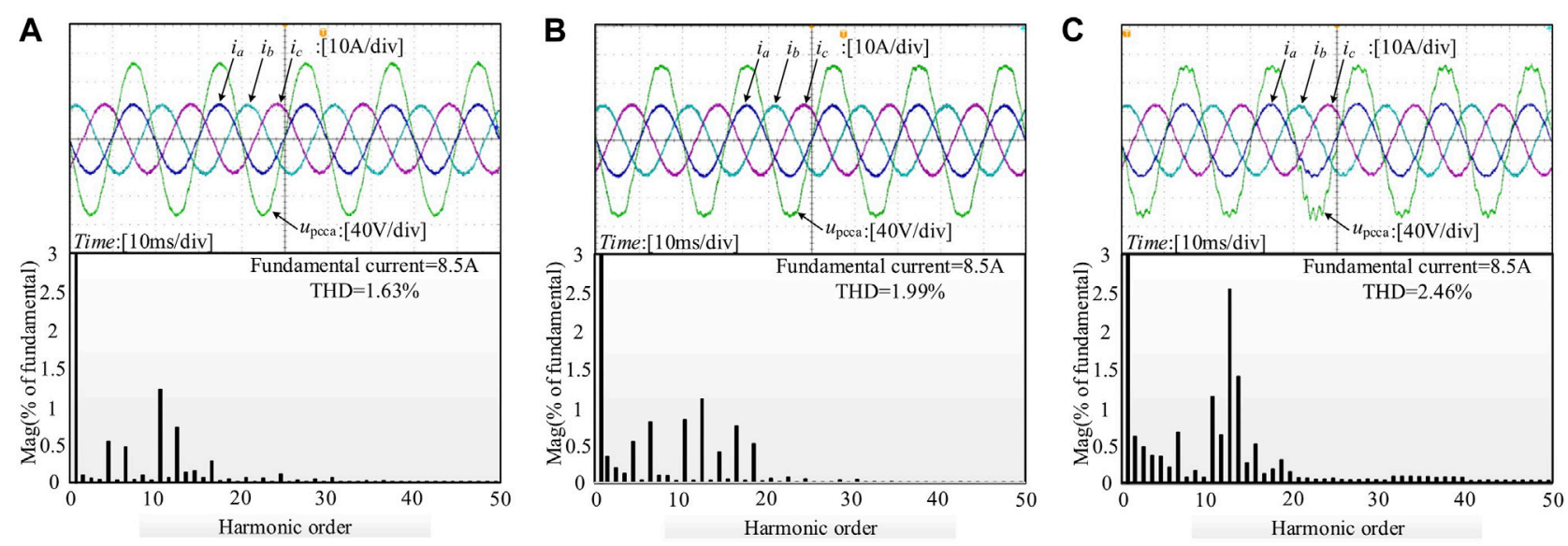

FIGURE 10 | Steady-state experimental waveforms of the inverter at $L_{g}=3 \mathrm{mH}$ : (A) with the proposed method in this paper, (B) with the method in $L_{i}$ et al. (2020), and $\mathbf{( C )}$ with the method in Jiao and Lee (2015).
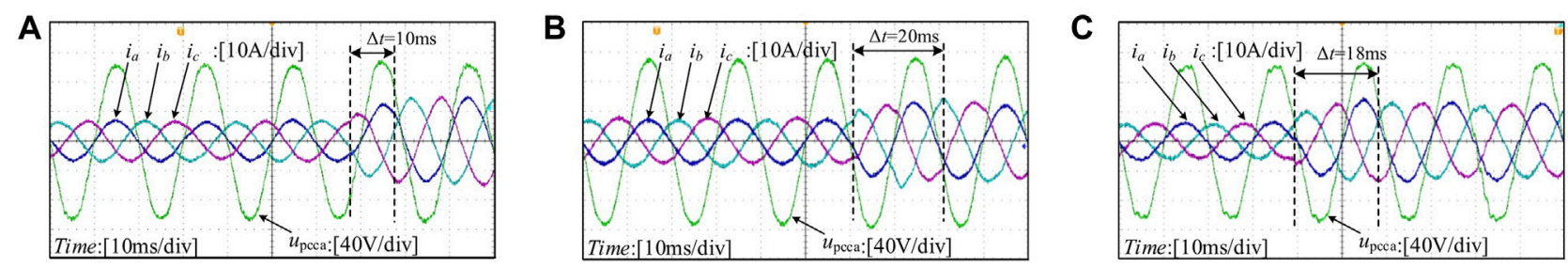

FIGURE 11 Dynamic experimental results of the inverter at $L_{g}=0 \mathrm{mH}$ : (A)) with the proposed method in this paper, (B) with the method in $L i u$ et al. (2020), and (C) with the method in Jiao and Lee (2015).
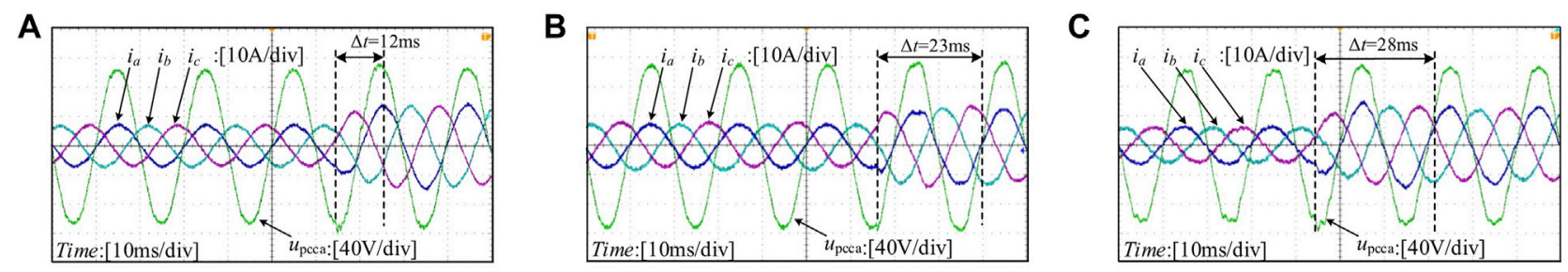

FIGURE 12 Dynamic experimental results of the inverter at $L_{g}=1.5 \mathrm{mH}$ : (A) with the proposed method in this paper, (B) with the method in Liu et al. (2020), and (C) with the method in Jiao and Lee (2015).
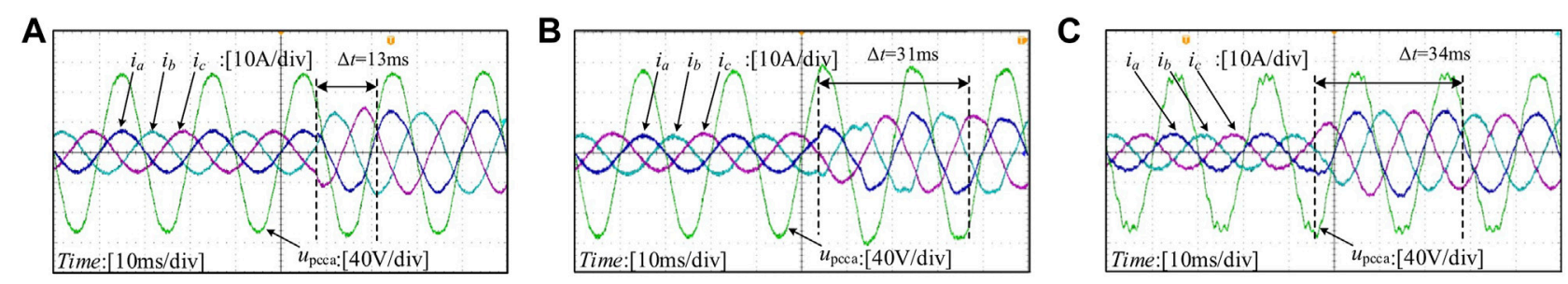

FIGURE 13|Dynamic experimental results of the inverter at $L_{g}=3 \mathrm{mH}$ : (A) with the proposed method in this paper, (B) with the method in Ref. Liu et al. (2020), and

(C) with the method in Jiao and Lee (2015). 
TABLE 3 | Comparison of dynamic performances with the three methods.

Grid conditions

The proposed method
in this paper
(ms)

10

$L_{g}=0 \mathrm{mH}$

$L_{g}=1.5 \mathrm{mH}$

$L_{g}=3 \mathrm{mH}$
13
Adjustment time

The method in

Liu et al. (2020) (ms)
The method in

Jiao and Lee.

(2015) (ms)

\section{CONCLUSION}

In order to improve the stability and dynamic performance of the three-phase LCL-filtered grid-connected inverter under the weak grid, based on the PR controller and active damping with only grid current feedback, a control parameter design method with multi-constrains considering system bandwidth for the inverter is proposed in this paper. According to the stability constraint, resonance suppression constraint, and margin constraint, the maximal bandwidth of the system with variation of $L_{g}$ is considered, which can ensure a better dynamic performance of the grid-connected inverter under the weak grid. Besides, the proposed method realizes resonance suppression more effectively and maintains a better performance for the inverter, compared with other two methods. With the parameters obtained from the proposed method, the experimental results show the better dynamic performance of the LCL filter in the weak grid with different grid impedances as well as the better steady-state performance and more effective resonance suppression.

\section{REFERENCES}

Busada, C. A., Jorge, S. G., and Solsona, J. A. (2005). Resonant Current Controller with Enhanced Transient Response for Grid-Tied Inverters. IEEE Trans. Ind. Appl. 65 (4), 1281-1291.

Cespedes, M., and Sun, J. (2014). Adaptive Control of Grid-Connected Inverters Based on Online Grid Impedance Measurements. IEEE Trans. Sustain. Energ. 5 (2), 516-523. doi:10.1109/tste.2013.2295201

Cespedes, M., and Sun, J. (2014). Impedance Modeling and Analysis of GridConnected Voltage-Source Converters. IEEE Trans. Power Electron. 29 (3), 1254-1261.

Chenlei Bao, C., Xuehua Wang, X., Donghua Pan, X., and Kailei, W. (2014). Stepby-Step Controller Design for LCL-type Grid-Connected Inverter with Capacitor-Current-Feedback Active-Damping. IEEE Trans. Power Electron. 29 (3), 1239-1253. doi:10.1109/tpel.2013.2262378

Dannehl, J., Fuchs, F. W., Hansen, S., and Thøgersen, P. B. (2010). Investigation of Active Damping Approaches for PI-Based Current Control of Grid-Connected Pulse Width Modulation Converters with LCL Filters. IEEE Trans. Ind. Applicat. 46 (4), 1509-1517. doi:10.1109/tia.2010.2049974

Dannehl, J., Liserre, M., and Fuchs, F. W. (2011). Filter-Based Active Damping of Voltage Source Converters with \$LCL\$ Filter. IEEE Trans. Ind. Electron. 58 (8), 3623-3633. doi:10.1109/tie.2010.2081952

Dorf, R. C., and Bishop, R. H. (2011). Modern Control Systems. 12th ed. Upper Saddle River, NJ: Prentice-Hall.

Etxegarai, A., Eguia, P., Torres, E., and Fernandez, E. (2012). Impact of Wind Power in Isolated Power Systems. In 2012 16th IEEE Mediterranean Electrotechnical Conference. Tunisia: Yasmine Hammamet, 63-66.

\section{DATA AVAILABILITY STATEMENT}

The original contributions presented in the study are included in the article/Supplementary Material, further inquiries can be directed to the corresponding author.

\section{AUTHOR CONTRIBUTIONS}

Theoretical promotion and manuscript edition, FW and JL; theoretical analysis and experiment, ZS and WX; simulation and analysis, ZL. All authors contributed to manuscript revision, read, and approved the submitted version.

\section{FUNDING}

This study was supported by the Natural Science Foundation of the Jiangsu Higher Education Institutions of China (Grant: 20KJB470029).

Geng, Y., Yun, Y., Chen, R., Wang, K., Bai, H., and Wu, X. (2018). Parameters Design and Optimization for LC-type Off-Grid Inverters with InductorCurrent Feedback Active Damping. IEEE Trans. Power Electron. 33 (1), 703-715. doi:10.1109/tpel.2017.2664812

Guan, Y., Wang, Y., Xie, Y., Liang, Y., Lin, A., and Wang, X. (2019). The DualCurrent Control Strategy of Grid-Connected Inverter with LCL Filter. IEEE Trans. Power Electron. 34 (6), 5940-5952. doi:10.1109/ tpel.2018.2869625

Hava, A. M., Lipo, T. A., and Erdman, W. L. (1995). Utility Interface Issues for Line Connected PWM Voltage Source Converters: a Comparative Study. In Proc.10th IEEE Appl. Power Electron. Conf. Expo. USA: TX, 125-132.

Holmes, D. G., Lipo, T. A., McGrath, B., and Kong, W. Y. (2017). Optimized Design of Stationary Frame Three Phase Ac Current Regulator. IEEE Trans. Power Electron. 24 (11), 3216-3228.

Ieee Recommended Practice and Requirements for Harmonic Control in Electric Power Systems (2014). IEEE Std 519-2014. (Revision of IEEE Std 519-1992), 3 Park Avenue. New York, USA.

Jiao, Y., and Lee, F. C. (2015). LCL Filter Design and Inductor Current Ripple Analysis for a Three-Level NPC Grid Interface Converter. IEEE Trans. Power Electron. 30 (9), 4659-4668. doi:10.1109/tpel.2014.2361907

Li, Y., Gao, W., Yan, W., Huang, S., Wang, R., Gevorgian, V., et al. (2021). Datadriven Optimal Control Strategy for Virtual Synchronous Generator via Deep Reinforcement Learning Approach. J. Mod. Power Syst. Clean. Energ. 9 (4), 919-929. doi:10.35833/mpce.2020.000267

Lindgren, M., and Svensson, J. (1998). Control of a Voltage-Source Converter Connected to the Grid through an LCL-Filter-Application to Active Filtering. in Proc. PESC. Fukuoka, Japan, 229-235. 
Liserre, M., Blaabjerg, F., and Hansen, S. (2005). Design and Control of an LCLFilter-Based Three-phase Active Rectifier. IEEE Trans. Ind. Applicat. 41 (5), 1281-1291. doi:10.1109/tia.2005.853373

Liserre, M., Blaabjerg, F., and Teodorescu, R. (2007). Grid Impedance Estimation via Excitation of \$LCL\$-Filter Resonance. IEEE Trans. Ind. Applicat. 43 (5), 1401-1407. doi:10.1109/tia.2007.904439

Liserre, M., Teodorescu, R., and Blaabjerg, F. (2006). Stability of Photovoltaic and Wind Turbine Grid-Connected Inverters for a Large Set of Grid Impedance Values. IEEE Trans. Power Electron. 21 (1), 263-272. doi:10.1109/tpel.2005.861185

Liu, T., Liu, J., Liu, Z., and Liu, Z. (2020). A Study of Virtual Resistor-Based Active Damping Alternatives for LCL Resonance in Grid-Connected Voltage Source Inverters. IEEE Trans. Power Electron. 35 (1), 247-262. doi:10.1109/tpel.2019.2911163

Lu, M., Wang, X., Loh, P. C., Blaabjerg, F., and Dragicevic, T. (2018). Graphical Evaluation of Time-Delay Compensation Techniques for Digitally Controlled Converters. IEEE Trans. Power Electron. 33 (3), 2601-2614. doi:10.1109/ tpel.2017.2691062

Malinowski, M., and Bernet, S. (2008). A Simple Voltage Sensorless Active Damping Scheme for Three-phase PWM Converters with an \$LCL\$ Filter. IEEE Trans. Ind. Electron. 55 (4), 1876-1880. doi:10.1109/tie.2008.917066

Parker, S. G., and McGrath, B. P. (2012). Regions of Active Damping Control for LCL Filters. In Proc. IEEE Energy Convers. Congr. Expo. Raleigh, USA, 53-60. doi:10.1109/ecce.2012.6342412

Pena-Alzola, R., Liserre, M., Blaabjerg, F., Ordonez, M., and Kerekes, T. (2014). A Self-Commissioning Notch Filter for Active Damping in a Three-phase LCL -Filter-Based Grid-Tie Converter. IEEE Trans. Power Electron. 29 (12), 6754-6761. doi:10.1109/tpel.2014.2304468

Sun, J. (2011). Impedance-Based Stability Criterion for Grid-Connected Inverters. IEEE Trans. Power Electron. 26 (11), 3075-3078. doi:10.1109/tpel.2011.2136439

Wang, X., Blaabjerg, F., and Loh, P. C. (2015). Grid-current-feedback Active Damping for LCL Resonance in Grid-Connected Voltage Source Converters. IEEE Trans. Power Electron. 31 (1), 213-223.

Wu, E., and Lehn, P. W. (2006). Digital Current Control of a Voltage Source Converter with Active Damping of LCL Resonance. IEEE Trans. Power Electron. 21 (5), 1364-1373. doi:10.1109/tpel.2006.880271

Xin, Z., Wang, X., Loh, P. C., and Blaabjerg, F. (2017). Grid-Current-Feedback Control for LCL-Filtered Grid Converters with Enhanced Stability. IEEE Trans. Power Electron. 32 (4), 3216-3228. doi:10.1109/tpel.2016.2580543

Xing, X., Zhang, C., Chen, A., Geng, H., and Qin, C. (2018). Deadbeat Control Strategy for Circulating Current Suppression in Multiparalleled Three-Level Inverters. IEEE Trans. Ind. Electron. 65 (8), 6239-6249. doi:10.1109/tie.2017.2786234

Xu, J., Xie, S., and Tang, T. (2013). Active Damping-Based Control for GridConnected LCL -filtered Inverter with Injected Grid Current Feedback Only. IEEE Trans. Ind. Electron. 61 (9), 4746-4758.
Xu, J., Xie, S., and Tang, T. (2013). Evaluations of Current Control in Weak Grid Case for Grid-connected LCL-filtered Inverter. IET Power Elect. 6 (2), 227-234. doi:10.1049/iet-pel.2012.0192

Xu, J., Xie, S., Zhang, B., and Qian, Q. (2018). Robust Grid Current Control with Impedance-phase Shaping for LCL-Filtered Inverters in Weak and Distorted Grid. IEEE Trans. Power Electron. 33 (12), 10240-10250. doi:10.1109/ tpel.2018.2808604

Yang, D., Ruan, X., and Wu, H. (2014). Impedance Shaping of the Grid-Connected Inverter with LCL Filter to Improve its Adaptability to the Weak Grid Condition. IEEE Trans. Power Electron. 29 (11), 5795-5805. doi:10.1109/ tpel.2014.2300235

Zhang, N., Sun, Q., Wang, J., and Yang, L. (2021). Distributed Adaptive Dual Control via Consensus Algorithm in the Energy Internet. IEEE Trans. Ind. Inf. 17 (7), 4848-4860. doi:10.1109/tii.2020.3031437

Zhou, L., Zhou, J. M. X., Lv, Y. Z., He, Z., Wu, W., Yang, L., et al. (2018). Inverter-Current-Feedback Resonance-Suppression Method for LCL-type DG System to Reduce Resonance-Frequency Offset and Grid-Inductance Effect. IEEE Trans. Ind. Electron. 65 (9), 7036-7048. doi:10.1109/ tie.2018.2795556

Zhu, K., Sun, P., Zhou, L., Du, X., and Luo, Q. (2020). Frequency-Division Virtual Impedance Shaping Control Method for Grid-Connected Inverters in a Weak and Distorted Grid. IEEE Trans. Power Electron. 35 (8), 8116-8129. doi:10.1109/tpel.2019.2963345

Zmood, D., and Holmes, D. (2003). Stationary Frame Current Regulation of PWM Inverters with Zero Steady-State Error. IEEE Trans. Power Electron. 18 (3), 3216-3228. doi:10.1109/tpel.2003.810852

Conflict of Interest: The authors declare that the research was conducted in the absence of any commercial or financial relationships that could be construed as a potential conflict of interest.

Publisher's Note: All claims expressed in this article are solely those of the authors and do not necessarily represent those of their affiliated organizations or those of the publisher, the editors, and the reviewers. Any product that may be evaluated in this article or claim that may be made by its manufacturer is not guaranteed or endorsed by the publisher.

Copyright (C) $2022 \mathrm{Wu}$, Sun, Xu, Li and Lyu. This is an open-access article distributed under the terms of the Creative Commons Attribution License (CC BY). The use, distribution or reproduction in other forums is permitted, provided the original author(s) and the copyright owner(s) are credited and that the original publication in this journal is cited, in accordance with accepted academic practice. No use, distribution or reproduction is permitted which does not comply with these terms. 


\section{NOMENCLATURE}

AD active damping

$C_{1}$ capacitor in the LCL filter

$f_{s}$ sampling frequency

$\boldsymbol{G}_{\mathbf{1}}$ transfer function from $u_{i}(s)$ to $i_{2}(s)$ for the LCL filter

$\boldsymbol{G}_{\boldsymbol{a}}$ transfer function of the $\mathrm{AD}$ loop

$\boldsymbol{G}_{\boldsymbol{c}}$ proportional resonance controller

$\boldsymbol{G}_{\boldsymbol{c l}}$ closed-loop transfer function of the system

$\boldsymbol{G}_{\boldsymbol{D}}$ total time delay model

GM gain margin

$\mathbf{G M}_{\mathbf{0}}$ ideal gain margin

$\boldsymbol{G}_{\boldsymbol{o p}}$ open-loop transfer function of the system

$i_{1}$ Inverter-side currents in the LCL filter

$\boldsymbol{i}_{2}$ grid-side currents in the LCL filter

$\boldsymbol{i}_{\mathrm{a}}, \boldsymbol{i}_{\mathrm{b}}, \boldsymbol{i}_{\mathrm{c}}$ three-phase grid currents

$I_{N}$ root mean square of grid current

$\boldsymbol{k}_{\boldsymbol{a d}} \mathrm{aD}$ coefficient

$\boldsymbol{k}_{\boldsymbol{a d} \_ \text {opt }}$ optimal AD parameter

$\boldsymbol{K}_{\mathbf{p w m}}$ gain of the PWM inverter

$\boldsymbol{K}_{\boldsymbol{p}}$ proportional gain of the PR controller

$\boldsymbol{K}_{\boldsymbol{p} \_ \text {opt }}$ optimal proportional gain of the PR controller

$\boldsymbol{K}_{\boldsymbol{r}}$ resonant gain of the PR controller

$\boldsymbol{L}_{\mathbf{1}}$ inverter-side inductor in the LCL filter
$\boldsymbol{L}_{2}$ grid-side inductor in the LCL filter

$\boldsymbol{L}_{\boldsymbol{g}}$ grid impedance

$\boldsymbol{L}_{\boldsymbol{g}_{-} \text {max }}$ maximum grid impedance

PCC point of common coupling

PM phase margin

$\mathbf{P M}_{\mathbf{0}}$ ideal phase margin

$\boldsymbol{R}_{\mathbf{e q}}$ virtual resistance in parallel with filter capacitor $C_{1}$

SCR short-circuit ratio

$T_{\boldsymbol{s}}$ sampling period

$\boldsymbol{u}_{\boldsymbol{i}}$ inverter output voltage

$\boldsymbol{U}_{\boldsymbol{s}}$ root mean square of grid voltage

$V_{\text {dc }}$ DC-bus voltage

$\boldsymbol{v}_{\text {pcca }}$ PCC voltage of phase A

$\boldsymbol{X}_{\mathbf{e q}}$ virtual reactance in parallel with filter capacitor $C_{1}$

$Z_{\text {eq }}$ virtual impedance in parallel with filter capacitor $C_{1}$

$\Delta \boldsymbol{t}$ adjustment time

$\boldsymbol{\omega}_{c}$ cutoff angular frequency of the system

$\boldsymbol{\omega}_{\boldsymbol{c}_{-} \max }$ maximum cutoff frequency of system

$\boldsymbol{\omega}_{\boldsymbol{h}}$ crossing frequency

$\boldsymbol{\omega}_{\boldsymbol{i}}$ cutoff angular frequency of the PR controller

$\omega_{o}$ grid fundamental angular frequency

$\boldsymbol{\omega}_{\text {res }}$ resonant frequency of the LCL filter

$\boldsymbol{\omega}_{\text {res }}{ }^{\prime}$ actual resonant frequency considering the $\mathrm{AD}$ loop 